\title{
Endophytic Fungal Diversity in Medicinal Plants of Western Ghats, India
}

\author{
Monnanda Somaiah Nalini, ${ }^{1}$ Ningaraju Sunayana, ${ }^{2}$ and Harischandra Sripathy Prakash ${ }^{2}$ \\ ${ }^{1}$ Department of Studies in Botany, University of Mysore, Manasagangotri, Mysore, Karnataka 570 006, India \\ ${ }^{2}$ Department of Studies in Biotechnology, University of Mysore, Manasagangotri, Mysore, Karnataka 570 006, India
}

Correspondence should be addressed to Monnanda Somaiah Nalini; nmsomaiah@gmail.com

Received 24 September 2013; Accepted 16 April 2014; Published 11 May 2014

Academic Editor: Raeid Abed

Copyright (C) 2014 Monnanda Somaiah Nalini et al. This is an open access article distributed under the Creative Commons Attribution License, which permits unrestricted use, distribution, and reproduction in any medium, provided the original work is properly cited.

\begin{abstract}
Endophytes constitute an important component of microbial diversity, and in the present investigation, seven plant species with rich ethnobotanical uses representing six families were analyzed for the presence of endophytic fungi from their natural habitats during monsoon (May/June) and winter (November/December) seasons of 2007. Fungal endophytes were isolated from healthy plant parts such as stem, root, rhizome, and inflorescence employing standard isolation methods. One thousand five hundred and twenty-nine fungal isolates were obtained from 5200 fragments. Stem fragments harbored more endophytes (80.37\%) than roots (19.22\%). 31 fungal taxa comprised of coelomycetes (65\%), hyphomycetes (32\%), and ascomycetes (3\%). Fusarium, Acremonium, Colletotrichum, Chaetomium, Myrothecium, Phomopsis, and Pestalotiopsis spp. were commonly isolated. Diversity indices differed significantly between the seasons $(P<0.001)$. Species richness was greater for monsoon isolations than winter. Host specificity was observed for few fungal endophytes. UPGMA cluster analysis grouped the endophytes into distinct clusters on the basis of genetic distance. This study is the first report on the diversity and host-specificity of endophytic fungal taxa were from the semi evergreen forest type in Talacauvery subcluster of Western Ghats.
\end{abstract}

\section{Introduction}

The microbes residing in the internal parts of plant tissues called "endophytes" constitute a group of plant symbionts and are a component of microbial diversity. Endophytes offer plethora of unknown advantages to the host with immense applications in agriculture and medicine [1,2]. Recently, challenging hypotheses related to endophyte diversity [3], their role in oxidative stress protection [4], heavy metal tolerance [5], and as components of tropical community ecology [6, 7] have emerged. A perusal of the literature over the past decades indicated many ethnomedicinal plant species with rich botanical history, sampled from unique ecological niches species are known to harbor potential endophytic microbes [8].

There has been an increasing surge of interest among the research groups for the isolation of endophytes from the tropical plant species $[9,10]$, owing to high plant diversity. One such region represents the Western Ghats, stretching a length of $1,600 \mathrm{Km}$ from the river Tapti in the state of Gujarat to the Southern tip of Kerala, recognized as one of the 34 hot spots of biodiversity. The Western Ghats represent rich flora with enormous species diversity as well as endemic taxa and are therefore recognized as one among the hot spots of the world [11]. Western Ghats are divided into seven subclusters. A proposal to include and declare 39 sites in this region as the World Natural Heritage Cluster Site by UNESCO is underway (http://www.atree.org/wg_unesco_whs).

India has many regions of unique ecological niche harboring variety of medicinal plants. One such region in the peninsular India is Kodagu District, the land of coffee cultivation. Kodagu is situated in the Western Ghats of peninsular India and is known for its majestic mountain ranges, coffee plantations, and teak wood forests. The Talacauvery subcluster $\left(12^{\circ} 17^{\prime}\right.$ to $12^{\circ} 27^{\prime} \mathrm{N}$ and $75^{\circ} 26^{\prime}$ to $\left.75^{\circ} 33^{\prime} \mathrm{E}\right)$ of the Western Ghats is situated in Kodagu. The altitude ranges from 1525 above mean sea level. Annual precipitation of $3525 \mathrm{~mm}$ is largely restricted during May to October, 
TABLE 1: Details of medicinal plants collected from the natural habitats of Talacauvery subcluster of Western Ghats.

\begin{tabular}{|c|c|c|c|c|c|}
\hline Plant species* & Common name & Ayurvedic name & Family & Habit & Parts collected \\
\hline $\begin{array}{l}\text { Tylophora asthmatica } \\
\text { (W. and A.) }\end{array}$ & Indian ipecacuanha & Anthrapachaka & Asclepiadaceae & Twiner & Stem \\
\hline Rubia cordifolia L. & Indian madder & Majith & Rubiaceae & Climber & Stem \\
\hline Plumbago zeylanica L. & White leadwort & Chitramool & Plumbaginaceae & Shrub & Stem \\
\hline $\begin{array}{l}\text { Phyllanthus amarus } \\
\text { (Schum. and Thonn.) }\end{array}$ & Niruri & Bhoomyamalaki & Euphorbiaceae & Herb & Stem and root \\
\hline Eryngium foetidum $\mathrm{L}$. & Fit weed/spiny/serrated coriander & Bhandhanya & Apiaceae & Herb & Roots and stem \\
\hline Centella asiatica L. & Asiatic pennywort & Gotu Kola & Apiaceae & Runner & Stolon, roots, and inflorescence \\
\hline Zingiber sp. & Wild ginger & Shunti & Zingiberaceae & Herb & Rhizome, aerial stem, and root \\
\hline
\end{tabular}

Ten plants* were sampled, pooled, and used for isolation of endophytes [13].

although premonsoon showers are not uncommon during February to April. The average temperature is $23^{\circ} \mathrm{C}$. Kodagu has a reservoir of forest belts and diverse vegetation ranging from tropical wet evergreen forests to scrub jungles. Several tribes residing in the forests still use medicinal plants of ethnopharmacological importance as the source of natural medication for their ailments [12]. Ethnomedicinal plants are often used in ayurvedic medicinal system in India for the treatment of various diseases.

Despite the reports of ethnomedicinal plants of this region, the biodiversity and the endophytic microbes of this region remain unexplored. Therefore, in the present investigation, seven medicinal plants representing six families were subjected to diversity studies on fungal endophytes during two seasons.

\section{Methodology}

2.1. Plant Materials and Study Site. Plant parts such as stem, root, rhizome, and inflorescence were collected from seven healthy medicinal plant species: Tylophora asthmatica, Rubia cordifolia, Plumbago zeylanica, Phyllanthus amarus, Eryngium foetidum, Centella asiatica, and Zingiber sp. inhabiting the natural vegetation of the Talacauvery Region of Western Ghats, located at $012^{\circ} 17^{\prime}$ to $012^{\circ} 27^{\prime} \mathrm{N}$ and $075^{\circ} 26^{\prime}$ to $075^{\circ} 33^{\prime} \mathrm{E}$ of Kodagu, Karnataka, during the monsoon (May to June) and winter seasons (November-December) of 2007 (Table 1). The natural vegetation is an evergreen/semievergreen type of forests. The mean temperature was $23^{\circ} \mathrm{C}$ and mean annual precipitation is $3525 \mathrm{~mm}$. Herbarium specimens of the plants were prepared and submitted to the herbarium collections in the DOS in Botany, University of Mysore. Ten individual plants from each were pooled for isolations. The samples were placed in polyethylene bags, labeled, transported in ice box to the laboratory, and placed in a refrigerator at $4^{\circ} \mathrm{C}$ until isolation. All samples were processed within $24 \mathrm{~h}$ of collection.

2.2. Isolation and Identification of Endophytic Fungi. Samples were washed thoroughly in distilled water, blot dried, and first immersed in $70 \%$ ethanol (v/v) for one min followed by second immersion in sodium hypochlorite $(3.5 \%, \mathrm{v} / \mathrm{v})$ for three minutes. They were rinsed three times in changes of sterile distilled water and dried on sterile blotters under the airflow to ensure complete drying. Bits of $1.0 \times 0.1 \mathrm{~cm}$ size were excised with the help of a sterile blade. A total of 5200 segments from stem, roots, inflorescence, and rhizomes of plant species were placed on water agar $(2.5 \%)$ supplemented with the antibiotic streptomycin sulphate $(100 \mathrm{mg} / \mathrm{L})$. Forty segments were plated per plate. The plates were wrapped in clean wrap cling film and incubated at $22^{\circ} \mathrm{C}$ with $12 \mathrm{~h}$ light and dark cycles for up to 6 to 8 weeks. The effectiveness of surface sterilization of tissues was checked by placing the aliquots of sterilants on agar plates and observing fungal colonies if any for two weeks [14].

Periodically the bits were examined for the appearance of fungal colony and each colony that emerged from segments was transferred to antibiotic-free potato dextrose agar medium (PDA, 2\%) to aid identification. The morphological identification of the isolates was done based on the fungal colony morphology and characteristics of the reproductive structures and spores [15-17]. Sporulation was induced by inoculating cultures onto sterilized banana leaf bits (one $\mathrm{cm}^{2}$ ) impregnated on potato dextrose agar in petri dishes. All fungal mounts were made on microscopic glass slides in lactophenol-cotton blue and sealed with nail polish. Cultures which failed to sporulate were grouped as mycelia sterilia. All the fungal isolates have been catalogued as DST\# series with plant code and maintained as culture collections of the department by cryopreservation on PDA overlaid with $15 \%$ glycerol $(\mathrm{v} / \mathrm{v})$ at $-20^{\circ} \mathrm{C}$ in a deep freezer.

2.3. Data Analysis. Isolation rate (IR), the measure of fungal richness of a sample, was calculated as the number of isolates obtained from tissue segments, divided by the total number of segments, and expressed as fractions but not as percentages [18]. The colonization frequency (CF), expressed as percentage, was calculated according to Kumaresan and Suryanarayanan [19] as follows:

$\% \mathrm{CF}=$

Number of tissue segments colonized by a fungus Total number of tissue segments plated $\times 100$. 


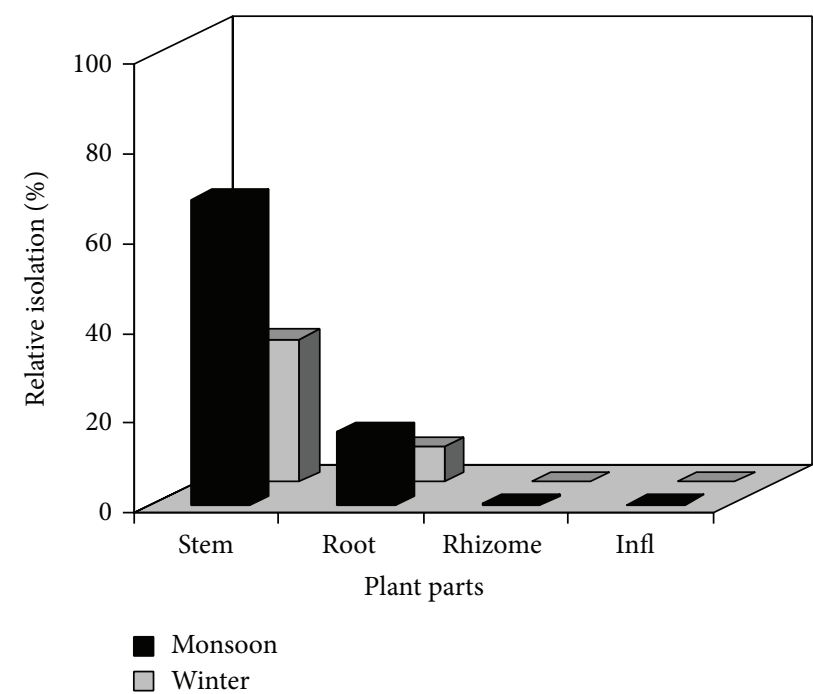

FIGURE 1: Relative seasonal isolations of fungal endophytes from plant parts of medicinal species.

The percentage of dominant endophytes $(D)$ was calculated based on the \%CF divided by the total number of endophytes $\times 100[20]$.

Differences in the extent of colonization of the samples were analyzed by univariant analysis of variance (oneway ANOVA) and Tukey's honestly significant difference (HSD) as post hoc test using the statistical software SPSS16.0. The fungal isolations were considered for analysis of ANOVA and Tukey's HSD. Simpson and Shannon diversity indices were calculated for endophytic fungi from different seasons with Estimate $S$, software (version 6, http://viceroy.eeb.uconn.edu/estimates/). Species richness was calculated using the online web page rarefactor calculator (http://www2.biology.ualberta.ca/jbrzusto/rarefact.php).

Rarefaction indices were employed to compare the species richness among the plant species during two seasons. The expected number of species in $N$ isolations was calculated [21]. Unweighted pair group method with arithmetic mean (UPGMA) cluster analysis was applied for all the isolates from plant species based on the number of isolates recovered from each plant species using a dendrogram constructed based on Nei's genetic distances [22] using tools for population genetics analysis (TFPGA) software [23].

\section{Results}

A total of 1529 isolates were obtained from 5200 tissue fragments from seven medicinal plant species. The extent of endophytes colonization varied in plant parts with stem fragments harboring $80 \%$ of endophytic isolates followed by root $(19.22 \%)$. In other plant parts, colonization was lower. Isolations of endophytes from various plant parts showed greater numbers of endophytes during monsoon than winter (Figure 1). The high isolation rates (IR) of fungal endophytes were recorded as 1.41 to 1.58 for $T$. asthmatica in both seasons, while in Zingiber sp., low rates of isolations

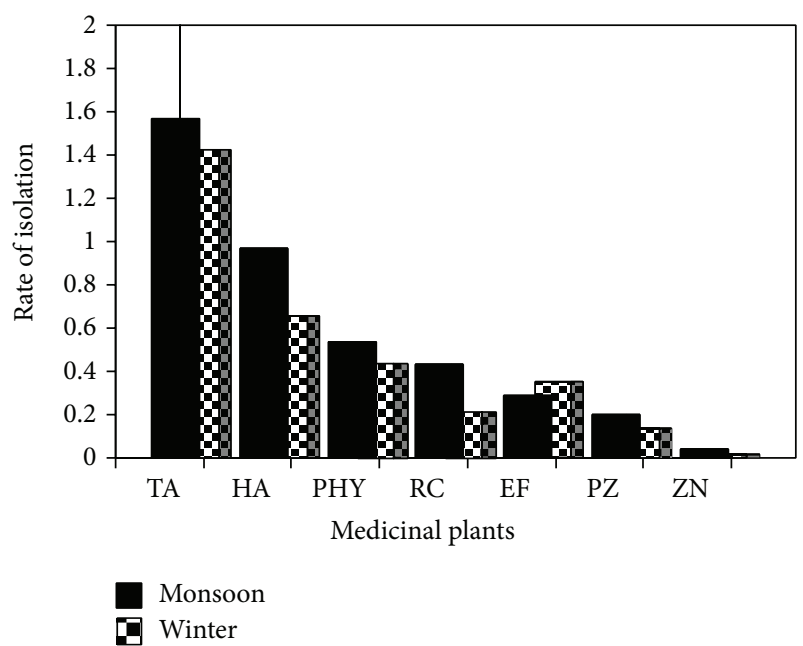

FIGURE 2: Seasonal isolation rates of fungal endophytes from medicinal species. Endophytic fungi were isolated from seven medicinal plant species during monsoon and winter seasons, respectively.

were obtained (Figure 2). Thirty-one fungal taxa were identified which consisted of coelomycetes (65\%), hyphomycetes (32\%), and ascomycete isolations of $3 \%$. The frequency of fungal colonization (\%CF) differed among the seven plant species (Table 2). Fusarium sp., Acremonium, Chaetomium, and Phoma are some of the endophytes with high colonization frequency. The dominant fungal genera include Fusarium spp. $(\% D=10.64)$ and Acremonium $(\% D=9.48)$. Few endophytic fungi such as A. strictum had wide distributions in host plants and were isolated from most plants with the exception of Zingiber sp. and Plumbago zeylanica, whereas species of Fusarium, Trichoderma, Curvularia, and Penicillium were isolated from more than three plant species.

Host-specificity was observed for few of the fungal endophytes isolated from two of the seven medicinal plants (Table 2). Colletotrichum dematium, Nigrospora oryzae, Heinesia rubi, Pestalotiopsis guepinii, and unidentified red pycnidial form were isolated from the stem segments of $T$. asthmatica only, while in Rubia cordifolia one endophytic Periconia exhibited specificity. $P$. islandicum and T. viride were isolated from root segments of Phyllanthus amarus.

Diversity indices of fungal endophytes varied within plant species as well as between seasons (Table 3). High ShannonWeiner diversity index was recorded for T. asthmatica $\left(H^{1}=\right.$ $2.60)$ and $P$. amarus $\left(H^{1}=2.27\right)$ during monsoon and winter seasons, whereas low indices were recorded for E. foetidum and Zingiber during monsoon and winter seasons, respectively. $42 \%$ of the total 31 taxa were found in monsoon season, while $55 \%$ of them colonized in both seasons. Simpson index $(1 / l)$ was high for $T$. asthmatica with a richness of 19 fungal species during monsoon season, while $P$. amarus recorded highest richness of species during winter season. Rarefaction curves calculated for the endophytic fungal isolations indicated maximum species richness for T. asthmatica and $P$. amarus during monsoon and winter isolations, respectively 


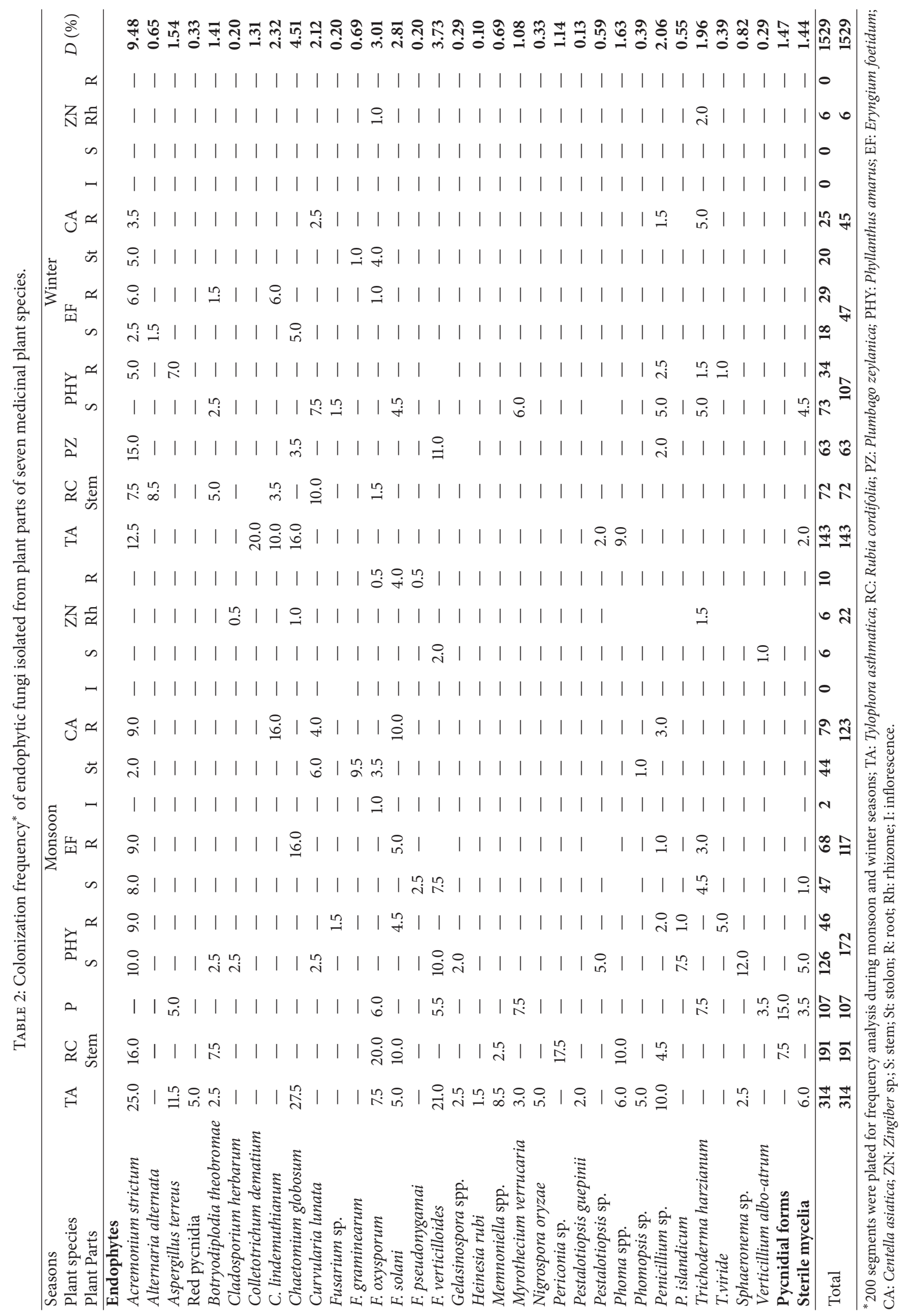


TABLE 3: Diversity indices $\left(H^{1}\right)$ and species richness of the medicinal plants.

\begin{tabular}{|c|c|c|c|c|c|c|c|c|}
\hline \multirow{3}{*}{ Plant species } & \multicolumn{2}{|c|}{ Monsoon } & \multirow{2}{*}{\multicolumn{2}{|c|}{ Diversity indices }} & \multicolumn{4}{|c|}{ Winter } \\
\hline & Total isolates & Total species richness & & & \multirow{2}{*}{ Total isolates } & \multirow{2}{*}{ Total species richness } & \multicolumn{2}{|c|}{ Diversity indices } \\
\hline & 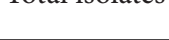 & 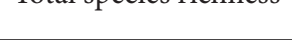 & Simpson & Shannon & & & Simpson & Shannon \\
\hline Tylophora asthmatica & 314 & 19 & 0.90 & 2.60 & 143 & 7.0 & 0.78 & 1.66 \\
\hline Rubia cordifolia & 191 & 9 & 0.86 & 2.05 & 72 & 6.0 & 0.79 & 1.62 \\
\hline Plumbago zeylanica & 107 & 8 & 0.84 & 1.96 & 63 & 4 & 0.63 & 1.14 \\
\hline Phyllanthus amarus & 172 & 14 & 0.87 & 2.29 & 107 & 11.0 & 0.89 & 2.27 \\
\hline Eryngium foetidum & 117 & 9 & 0.77 & 1.68 & 47 & 6 & 0.75 & 1.53 \\
\hline Centella asiatica & 123 & 8 & 0.83 & 1.88 & 45 & 6 & 0.76 & 1.57 \\
\hline Zingiber sp. & 22 & 8 & 0.79 & 1.81 & 6 & 2 & 0.44 & 0.64 \\
\hline
\end{tabular}
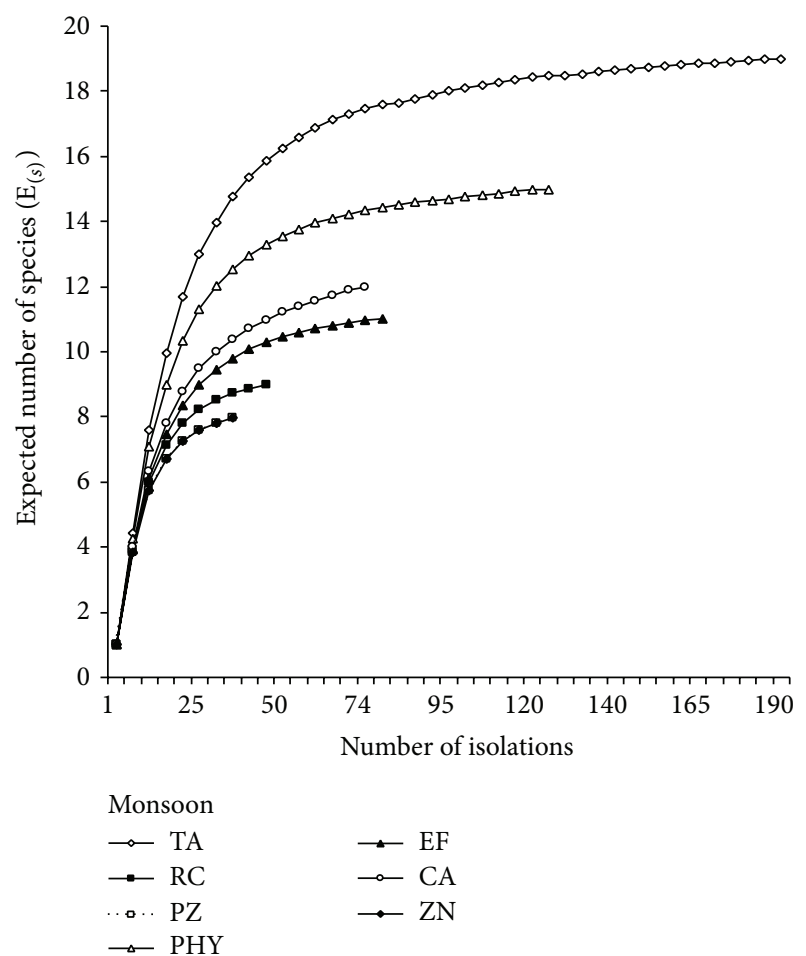

FIgURE 3: Rarefaction curvesof fungal endophytes from monsoon isolations (number of isolations versus expected number of species $\left.\mathrm{E}_{(s)}\right)$. TA: Tylophora asthmatica; RC: Rubia cordifolia; PZ: Plumbago zeylanica; PHY: Phyllanthus amarus; EF: Eryngium foetidum; CA: Centella asiatica; and ZN: Zingiber sp.

(Figures 3 and 4). Differences in the number of isolates and colonization frequency differed significantly between seasons $(P<0.001)$ as indicated in Table 4 .

Nei's genetic distance between endophytes isolated from plant species ranged from 0.3185 (between populations of Zingiber and C. asiatica) to 0.9116 (between populations of Zingiber and T. asthmatica) (Table 5) which was widely ranged. This indicates a closer relationship between endophytic fungal patterns of both plants. In general, fungal species from T. asthmatica is most distanced from the other

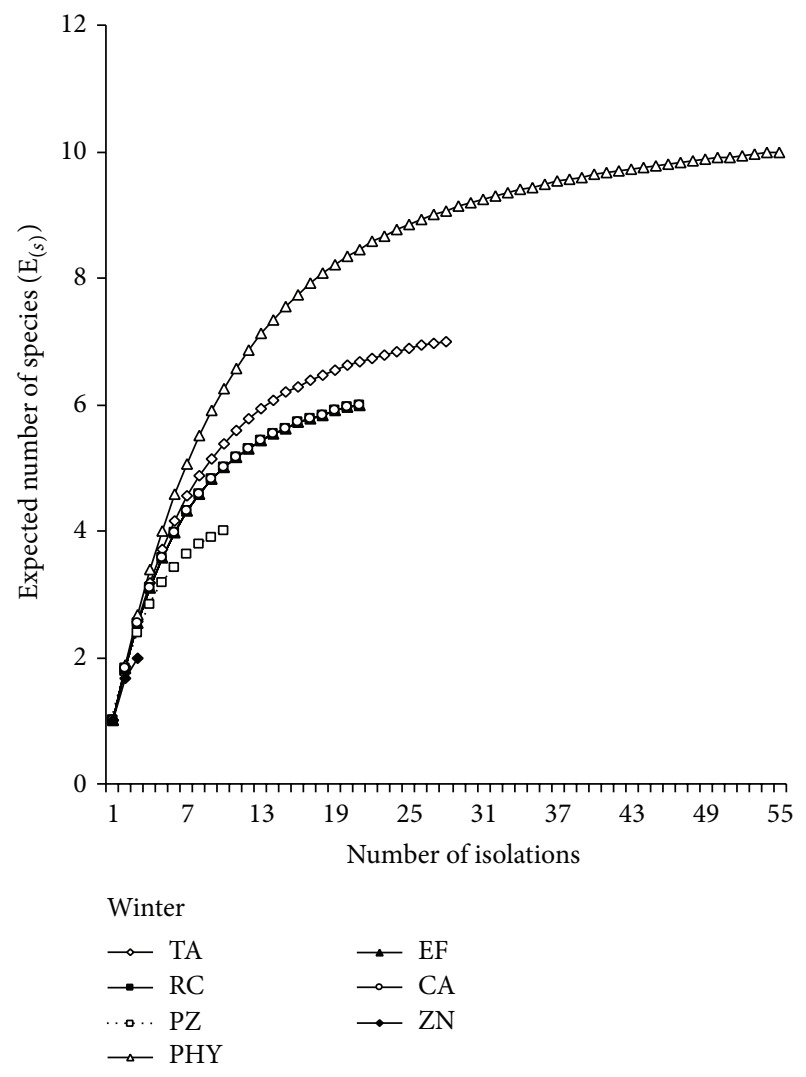

FIGURE 4: Rarefaction curves of fungal endophytes from winter isolations (number of isolations versus expected number of species $\left.\mathrm{E}_{(s)}\right)$. TA: Tylophora asthmatica; RC: Rubia cordifolia; PZ: Plumbago zeylanica; PHY: Phyllanthus amarus; EF: Eryngium foetidum; CA: Centella asiatica; and ZN: Zingiber sp.

plants studied. In order to represent the relationships among plant species, cluster analysis (UPGMA) was used to generate a dendrogram based on Nei's genetic distances between populations (Figure 5). In this dendrogram, all plants form a distinct cluster. When the transect line was placed at approximately 0.4 on the distance scale, two distinct groups were formed. The first cluster was formed by CA-ZN, while 
TABLE 4: ANOVA table of seasonal variation of endophytic fungi analyzed from seven medicinal plant species.

\begin{tabular}{lccccc}
\hline & Sum of squares & Degrees of freedom & Mean $^{2}$ & $F$ & Significance \\
\hline Between seasons & 11931.9 & 26 & 458.919 & 34.382 & 0.001 \\
Within seasons & 1001.062 & 75 & 13.346 & - & - \\
\hline Total & $\mathbf{1 2 9 3 2 . 9 6}$ & $\mathbf{1 0 1}$ & - & - \\
\hline
\end{tabular}

TABLE 5: Nei's genetic distance of plant species analyzed for endophytic fungi.

\begin{tabular}{lccccccc}
\hline & TA & RC & PZ & PHY & EF & CA & ZN \\
\hline TA & $* * *$ & 0.7885 & 0.5008 & 0.6061 & 0.4055 & 0.7885 & 0.9116 \\
RC & & $* * *$ & 0.5008 & 0.7239 & 0.4055 & 0.3610 & 0.6061 \\
PZ & & $* * *$ & 0.6633 & 0.3610 & 0.5008 & 0.4520 \\
PHY & & & $* * *$ & 0.4520 & 0.5008 & 0.6633 \\
EF & & & & $* * *$ & 0.4055 & 0.3610 \\
CA & & & & & & $* * *$ & 0.3185 \\
ZN & & & & & & & $* * *$ \\
\hline
\end{tabular}

${ }^{*}$ Indicates that genetic distance between the same genus does not exist, it is shown for different genera.

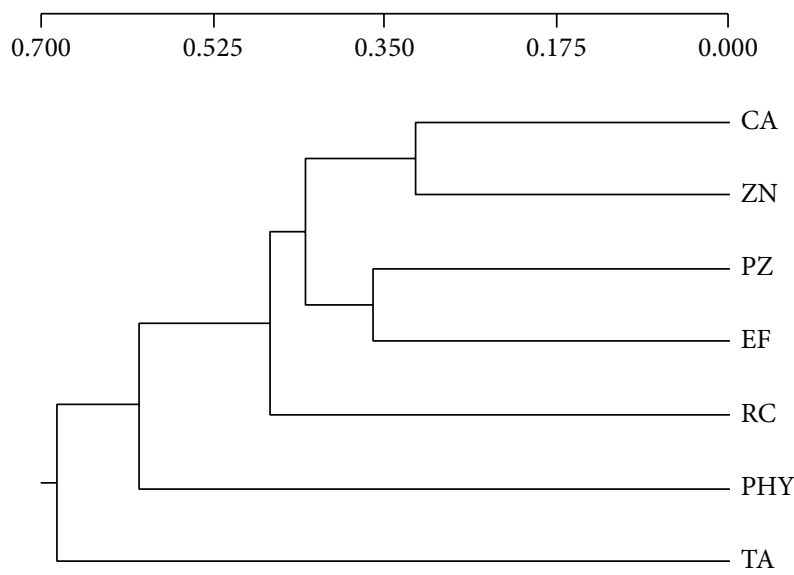

FIGURE 5: UPGMA cluster analysis of fungal endophytes representing seven medicinal plant species. Plant codes are TA: Tylophora asthmatica; RC: Rubia cordifolia; PZ: Plumbago zeylanica; PHY: Phyllanthus amarus; EF: Eryngium foetidum; CA: Centella asiatica; and ZN: Zingiber sp.

PZ-EF formed the second cluster. PHY, RC, and TA are found outside the cluster.

\section{Discussion}

Medicinal plants are considered as a repository of "endophytic microbes" living in the internal tissues of plants. The quest for identifying novel bioactives from the endophytic fungi has resulted in the sampling of host plants such as herbs, shrubs, tree species, and vines in unique places of ecological adaptations around the rainforests of the world. Such niches harbor great species diversity, unintervened by human activities. Efforts in this direction to sample plants located in the rainforests around the world with potential ethnomedicinal values have resulted in the isolation of fungal endophytes, unique to a particular plant species with distinct bioactivity.

4.1. Endophyte Colonization in Medicinal Species. The medicinal plant species were sampled from the Talacauvery subcluster situated in the Kodagu District of Western Ghats of Southern India. This region is among one of the 34 hot spots of biodiversity. Recently, a proposal to include this biodiversity spot in the list of UNESCO Heritage cluster site is underway (http://www.atree.org/wg_unesco_whs). The natives as well as the ethnic tribes inhabiting this region still depend on the plants as a source of medicine to cure some of the ailments [12]. Seven medicinal plant species assigned to six plant families were selected for the study in natural populations in two seasons from a single location from the study area stretching over an area of 25 kilometers. Sampling was conducted during monsoon and winter seasons, as two of the herbaceous species, E. foetidum and Zingiber sp., grow only till the second half of the year (June to December) and their nonavailability during summer (March to May) makes it difficult to consider the summer season for endophytic analysis.

From 5200 segments of plant materials a total of 1529 isolates were obtained; these were grouped into 31 taxa. Mycelia sterilia, the fungal taxa that failed to sporulate, were also reported from this study. This fungal group is prevalent in endophytic studies [24]. The fungal endophytes were analyzed from four plant parts, namely, stem, root, rhizome, and inflorescence; however, their occurrence in root and inflorescence was investigated for few plant species only, as the phenology and sampling of plants never correlated with seasons. The leaves were not considered for isolations since some of the plants were climbers and stragglers with delicate hairy surfaces and stringent surface sterilization techniques would render them unsuitable for plating on agar medium. Relative percentages of endophytic isolations from stem segments were greater $(80.37 \%)$ than isolations from roots (19.22\%). Our results are supported by the earlier work of Huang et al. [25] on 29 traditional Chinese medicinal plants that fungal endophytes are more frequent in stem tissues than roots. Among the fungal taxa, coelomycete isolations were more dominant than hyphomycetes and have been found in earlier studies in endophytes of tree species [26].

Endophytes such as Colletotrichum, Phoma, Acremonium, Chaetomium, Botryodiplodia, and Trichoderma were isolated with $\% D>2.0$. Few fungal taxa that are less frequently isolated are Pestalotiopsis, Penicillium islandicum, Cladosporium herbarum, Alternaria alternata, F. graminearum, Phomopsis, 
and Sphaeronema. Colletotrichum spp. are the most frequently encountered endophytic fungi [18], whereas Pestalotiopsis spp. are well documented as endophytes of many rainforest plants $[27,28]$, tropical tree species, namely, Terminalia arjuna [29], Azadirachta indica [30], and many herbs and shrubs $[25,31,32]$. It is necessary to screen newer plant species for the isolation of fungal endophytes, as Hawksworth and Rossman [33] estimate that there are still millions of species of fungi yet to be identified. Differences in the colonization frequencies of endophytes during two seasons were observed and more isolation during monsoon season is due to the fact that the slimy conidia of fungal spores are dispersed better by rain splashes and germination of conidia is influenced by climatic factors [34].

4.2. Host-Specificity of Fungal Endophytes. We observed that some fungal taxa exhibited host-specificity, a phenomenon often associated with endophytes. Three plant species, $T$. asthmatica, $R$. cordifolia, and P. amarus, were host-specific to endophytes. The red pycnidial endophyte (TA-005) was isolated from the stem fragments of T. asthmatica only, suggesting the host-specificity of this endophyte. Pestalotiopsis guepinii was isolated from the stem segments of $T$. asthmatica. It has been reported as an endophyte of Wollemia nobilis, growing in Sydney, Australia [35]. Heinesia rubi, $P$. islandicum, and TA-005 are new reports of fungi as endophytes. Host-specificity of endophytic fungi has been observed earlier for grasses [36], orchids [37], and forest tree species [38, 39]. Recently, Sun et al. [40] reiterated the term "host-specificity" as taxa that occur exclusively on a stated host but not on other hosts in the same habitat [41]. Our studies also indicate the host-specificity of endophytes as the plant species were sampled from a single habitat.

4.3. Seasonal Diversity of Fungal Endophytes. Diversity indices for fungal endophytes as analyzed by ShannonWeiner $\left(H^{1}\right)$ and Simpson $(1 / l)$ indices indicated differences in seasonal variation and species richness. High indices were noted for T. asthmatica $\left(H^{1}=2.6\right)$ and P. amarus $\left(H^{1}=2.27\right)$ during monsoon and winter seasons, respectively. The fungal species did not differ significantly between plant species, whereas they differed between seasons $(P<0.001)$. Seasonal variation in fungal isolates and colonization frequency has been reported for many host plants [42, 43]. High colonization frequency as well as the species richness of endophytic fungi is limited to leaf segments rather than stem or bark segments of host plants sampled from five medicinal species of Kudremukh Region of Western Ghats [44]. Species richness in our study is limited to stem fragments among the plant parts considered for analysis.

Most studies on fungal endophytes in tropics have revealed remarkable patterns of endophyte colonization and estimates of diversity in foliages of forest tree species representing various sites such as Panamanian Forest [45] and Iwokrama Forest Reserve, Guyana [39]. In the Nilgiri Biosphere Reserve, Western Ghats, India, 75 dicotyledonous species in three different tropical forest types were sampled to study foliar endophytes and diversity [10]. The endophyte diversity in forest types was limited due to loose host affiliations among endophytes. Studies on foliar endophytes from the sampling of herbaceous and shrubby medicinal plant species have revealed differences in the colonization rates as well as seasonal diversity in Malnad Region of Bhadra Wildlife Sanctuary in Southern India [32, 46].

The present study provides firsthand information on the diversity and seasonal influence on the colonization frequencies of endophytic fungi from selected medicinal plants from one of the subclusters of biodiversity hot spots in the Western Ghats of Southern India. Although the isolation and analysis of endophyte communities in herbs, shrubs, and trees are not uncommon, each of the studies is unique with reference to number of hosts, species of fungal endophytes, and their specificity. The fungal endophytes have been subjected to fermentation studies, and extracts are being tested for biological activities.

\section{Conclusion}

The study provides firsthand information on the diversity and seasonal influence on the colonization frequencies of endophytic fungi from seven medicinal plants from one of the subclusters of biodiversity hot spots in the Western Ghats of Southern India. The present investigation is the first isolation of endophytes from the medicinal species and their plant parts. Though isolation of endophytes has been accomplished from various forest types and locations around the globe, each study is unique in documenting newer endophytic taxa. We are currently working on the fermentation of fungal endophytes to obtain newer antioxidants with therapeutic applications.

\section{Conflict of Interests}

The authors declare no conflict of interests regarding the publication of this paper.

\section{Acknowledgments}

This work was carried out with the financial assistance from the Department of Science \& Technology (DST)-SERC Division, Government of India, under the Women Scientist Scheme [DST-WOS (A)] awarded to Monnanda Somaiah Nalini (DST sanction no. SR/WOS (A)/LS-76/2006 dt. 02.08.2007). Monnanda Somaiah Nalini is thankful to the Chairman, DOS in Biotechnology, for providing the necessary facilities for the completion of the project.

\section{References}

[1] K. Clay, J. Holah, and J. A. Rudgers, "Herbivores cause a rapid increase in hereditary symbiosis and alter plant community composition," Proceedings of the National Academy of Sciences of the United States of America, vol. 102, no. 35, pp. 12465-12470, 2005.

[2] P. Álvarez-Loayza, J. F. White Jr., M. S. Torres et al., "Light converts endosymbiotic fungus to pathogen, influencing seedling 
survival and niche-space filling of a common tropical tree, Iriartea deltoidea," PloS ONE, vol. 6, no. 1, 2011.

[3] R. Linnakoski, H. Puhakka-tarvainen, and A. Pappinen, "Endophytic fungi isolated from Khaya anthotheca in Ghana," Fungal Ecology, vol. 5, no. 3, pp. 298-308, 2012.

[4] J. F. White Jr. and M. S. Torres, "Is plant endophyte-mediated defensive mutualism the result of oxidative stress protection?" Physiologia Plantarum, vol. 138, no. 4, pp. 440-446, 2010.

[5] H.-Y. Li, D.-W. Li, C.-M. He, Z.-P. Zhou, T. Mei, and H.-M. $\mathrm{Xu}$, "Diversity and heavy metal tolerance of endophytic fungi from six dominant plant species in a $\mathrm{Pb}-\mathrm{Zn}$ mine wasteland in China," Fungal Ecology, vol. 5, no. 3, pp. 309-315, 2012.

[6] A. E. Arnold, "Understanding the diversity of foliar endophytic fungi: progress, challenges, and frontiers," Fungal Biology Reviews, vol. 21, no. 2-3, pp. 51-66, 2007.

[7] K. D. Hyde and K. Soytong, "The fungal endophyte dilemma," Fungal Diversity, vol. 33, pp. 163-173, 2008.

[8] G. Strobel and B. Daisy, "Bioprospecting for microbial endophytes and their natural products," Microbiology and Molecular Biology Reviews, vol. 67, no. 4, pp. 491-502, 2003.

[9] A. E. Arnold and F. Lutzoni, "Diversity and host range of foliar fungal endophytes: are tropical leaves biodiversity hotspots?" Ecology, vol. 88, no. 3, pp. 541-549, 2007.

[10] T. S. Suryanarayanan, T. S. Murali, N. Thirunavukkarasu, M. B. Govinda Rajulu, G. Venkatesan, and R. Sukumar, "Endophytic fungal communities in woody perennials of three tropical forest types of the Western Ghats, southern India," Biodiversity and Conservation, vol. 20, no. 5, pp. 913-928, 2011.

[11] R. A. Mittermeier, N. Myers, P. R. Gil, and C. G. Mittermeier, Hotspots: Earth's Biologically Richest and Most Endangered Terrestrial Ecoregions, Cemex Conservation International, Washington, DC, USA, 2000.

[12] R. D. Kshirsagar and N. P. Singh, "Some less known ethnomedicinal uses from Mysore and Coorg districts, Karnataka state, India," Journal of Ethnopharmacology, vol. 75, no. 2-3, pp. 231-238, 2001.

[13] N. Yoganarasimhan, Medicinal Plants of India, Karnataka Interline Publishing, Bangalore, India, 1996.

[14] B. Schulz, U. Wanke, S. Draeger, and H. J. Aust, "Endophytes from herbaceous plants and shrubs: effectiveness of surface sterilization methods," Mycological Research, vol. 97, no. 12, pp. 1447-1450, 1993.

[15] H. Barnett and B. Hunter, Illustrated Genera of Imperfect Fungi, Burgess Publishing, Minneapolis, Minn, USA, 1998.

[16] K. H. Domsch, W. Gams, and T. Anderson, Compendium of Soil Fungi, Academic Press, New York, NY, USA, 2003.

[17] J. F. Leslie and B. A. Summerell, The Fusarium Laboratory Manual, Blackwell Publishing, London, UK, 2006.

[18] W. Photita, P. W. J. Taylor, R. Ford, K. D. Hyde, and S. Lumyong, "Morphological and molecular characterization of Colletotrichum species from herbaceous plants in Thailand," Fungal Diversity, vol. 18, pp. 117-133, 2005.

[19] V. Kumaresan and T. S. Suryanarayanan, "Occurrence and distribution of endophytic fungi in a mangrove community," Mycological Research, vol. 105, no. 11, pp. 1388-1391, 2001.

[20] V. Kumaresan and T. S. Suryanarayanan, "Endophyte assemblages in young, mature and senescent leaves of Rhizophora apiculata: evidence for the role of endophytes in mangrove litter degradation," Fungal Diversity, vol. 9, pp. 81-91, 2002.

[21] J. A. Ludwig and J. F. Reynolds, Statistical Ecology: A Primer on Methods and Computing, John Wiley \& Sons, New York, NY, USA, 1988.

[22] M. Nei, "Genetic distance between populations," American Naturalist, vol. 106, no. 949, pp. 283-293, 1972.

[23] M. P. Miller, Tools For Population Genetic Analyses (TFPGA) $V$ L.3: A Windows program For the Analysis of Allozyme And moleculAr Genetic data, Department of Biological Sciences, Northern Arizona University, Flagstaff, Ariz, USA, 1997.

[24] D. C. Lacap, K. D. Hyde, and E. C. Y. Liew, "An evaluation of the fungal 'morphotype' concept based on ribosomal DNA sequences," Fungal Diversity, vol. 12, pp. 53-66, 2003.

[25] W. Y. Huang, Y. Z. Cai, K. D. Hyde, H. Corke, and M. Sun, "Biodiversity of endophytic fungi associated with 29 traditional Chinese medicinal plants," Fungal Diversity, vol. 33, pp. 61-75, 2008.

[26] M. V. Tejesvi, B. Mahesh, M. S. Nalini et al., "Fungal endophyte assemblages from ethnopharmaceutically important medicinal trees," Canadian Journal of Microbiology, vol. 52, no. 5, pp. 427435, 2006.

[27] N. Raj, Coelomycetous Anamorphs With Appendage Bearing Conidia, Edwards Brothers, Ann Harbor, Michigan, 1993.

[28] G. A. Strobel, "Microbial gifts from rain forests," Canadian Journal of Plant Pathology, vol. 24, no. 1, pp. 14-20, 2002.

[29] M. V. Tejesvi, B. Mahesh, M. S. Nalini et al., "Endophytic fungal assemblages from inner bark and twig of Terminalia arjuna W. \& A. (Combretaceae)," World Journal of Microbiology and Biotechnology, vol. 21, no. 8-9, pp. 1535-1540, 2005.

[30] B. Mahesh, M. V. Tejesvi, M. S. Nalini et al., "Endophytic mycoflora of inner bark of Azadirachta indica A. Juss," Current Science, vol. 88, no. 2, pp. 218-219, 2005.

[31] K. Rajagopal, S. Kalavathy, S. Kokila et al., "Diversity of fungal endophytes in few medicinal herbs of southern India," Asian Journal of Experimental Biological Sciences, vol. 1, pp. 415-418, 2010.

[32] Y. L. Krishnamurthy, S. B. Naik, and S. Jayaram, "Fungal communities in herbaceous medicinal plants from the malnad region, Southern India," Microbes and Environments, vol. 23, no. 1, pp. 24-28, 2008.

[33] D. L. Hawksworth and A. Y. Rossman, "Where are all the undescribed fungi?” Phytopathology, vol. 87, no. 9, pp. 888-891, 1997.

[34] D. Wilson and G. C. CarrolL, "Infection studies of Discula quercina, an endophyte of Quercus garryana," Mycologia, vol. 86, no. 5, pp. 635-647, 1994.

[35] G. A. Strobel, W. M. Hess, J.-Y. Li et al., "Pestalotiopsis guepinii, a taxol-producing endophyte of the wollemi pine, Wollemia nobilis," Australian Journal of Botany, vol. 45, no. 6, pp. 10731082, 1997.

[36] K. Clay, "Fungal endophytes of grasses," Annual Review of Ecology and Systematics, vol. 21, no. 1, pp. 275-297, 1990.

[37] P. Bayman, L. L. Lebrón, R. L. Tremblay, and D. J. Lodge, "Variation in endophytic fungi from roots and leaves of Lepanthes (Orchidaceae)," New Phytologist, vol. 135, no. 1, pp. 143-149, 1997.

[38] A. E. Arnold, Z. Maynard, and G. S. Gilbert, "Fungal endophytes in dicotyledonous neotropical trees: patterns of abundance and 
diversity," Mycological Research, vol. 105, no. 12, pp. 1502-1507, 2001.

[39] P. F. Cannon and C. M. Simmons, "Diversity and host preference of leaf endophytic fungi in the Iwokrama Forest Reserve, Guyana," Mycologia, vol. 94, no. 2, pp. 210-220, 2002.

[40] X. Sun, Q. Ding, K. D. Hyde, and L. D. Guo, "Community structure and preference of endophytic fungi of three woody plants in a mixed forest," Fungal Ecology, vol. 5, no. 5, pp. 624632, 2012.

[41] P. Holliday, A Dictionary of Plant Pathology, Cambridge University Press, Cambridge, UK, 1998.

[42] J. Collado, G. Platas, and F. Peláez, "Identification of an endophytic Nodulisporium sp. from Quercus ilex in central Spain as the anamorph of Biscogniauxia mediterranea by rDNA sequence analysis and effect of different ecological factors on distribution of the fungus," Mycologia, vol. 93, no. 5, pp. 875886, 2001.

[43] X.-X. Gao, H. Zhou, D.-Y. Xu, C.-H. Yu, Y.-Q. Chen, and L.-H. $\mathrm{Qu}$, "High diversity of endophytic fungi from the pharmaceutical plant, Heterosmilax japonica Kunth revealed by cultivationindependent approach," FEMS Microbiology Letters, vol. 249, no. 2, pp. 255-266, 2005.

[44] N. S. Raviraja, "Fungal endophytes in five medicinal plant species from Kudremukh Range, Western Ghats of India," Journal of Basic Microbiology, vol. 45, no. 3, pp. 230-235, 2005.

[45] A. E. Arnold, Z. Maynard, G. S. Gilbert, P. D. Coley, and T. A. Kursar, "Are tropical fungal endophytes hyperdiverse?" Ecology Letters, vol. 3, no. 4, pp. 267-274, 2000.

[46] B. S. Naik, J. Shashikala, and Y. L. Krishnamurthy, "Diversity of fungal endophytes in shrubby medicinal plants of Malnad region, Western Ghats, Southern India," Fungal Ecology, vol. 1, no. 2-3, pp. 89-93, 2008. 

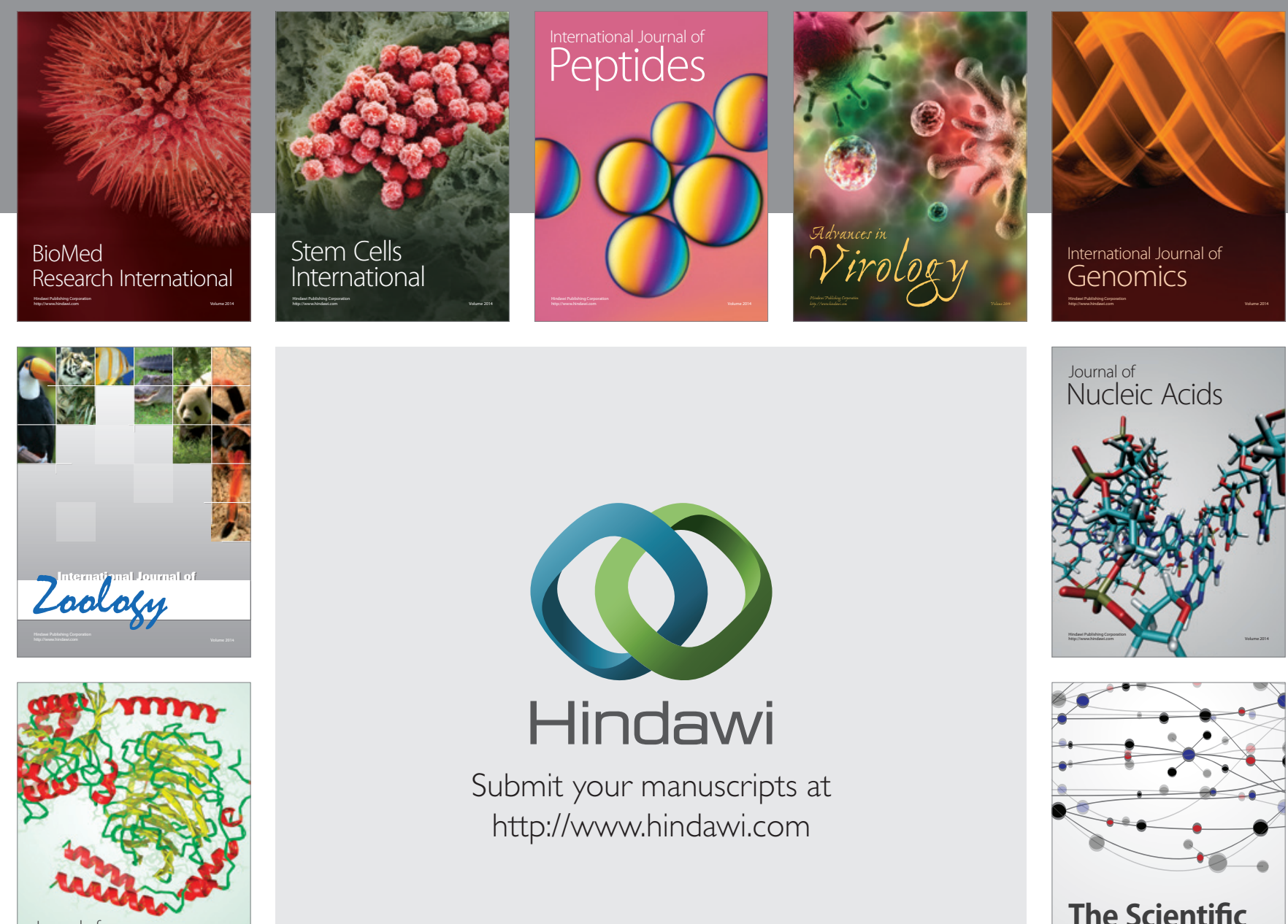

Submit your manuscripts at

http://www.hindawi.com

Journal of
Signal Transduction
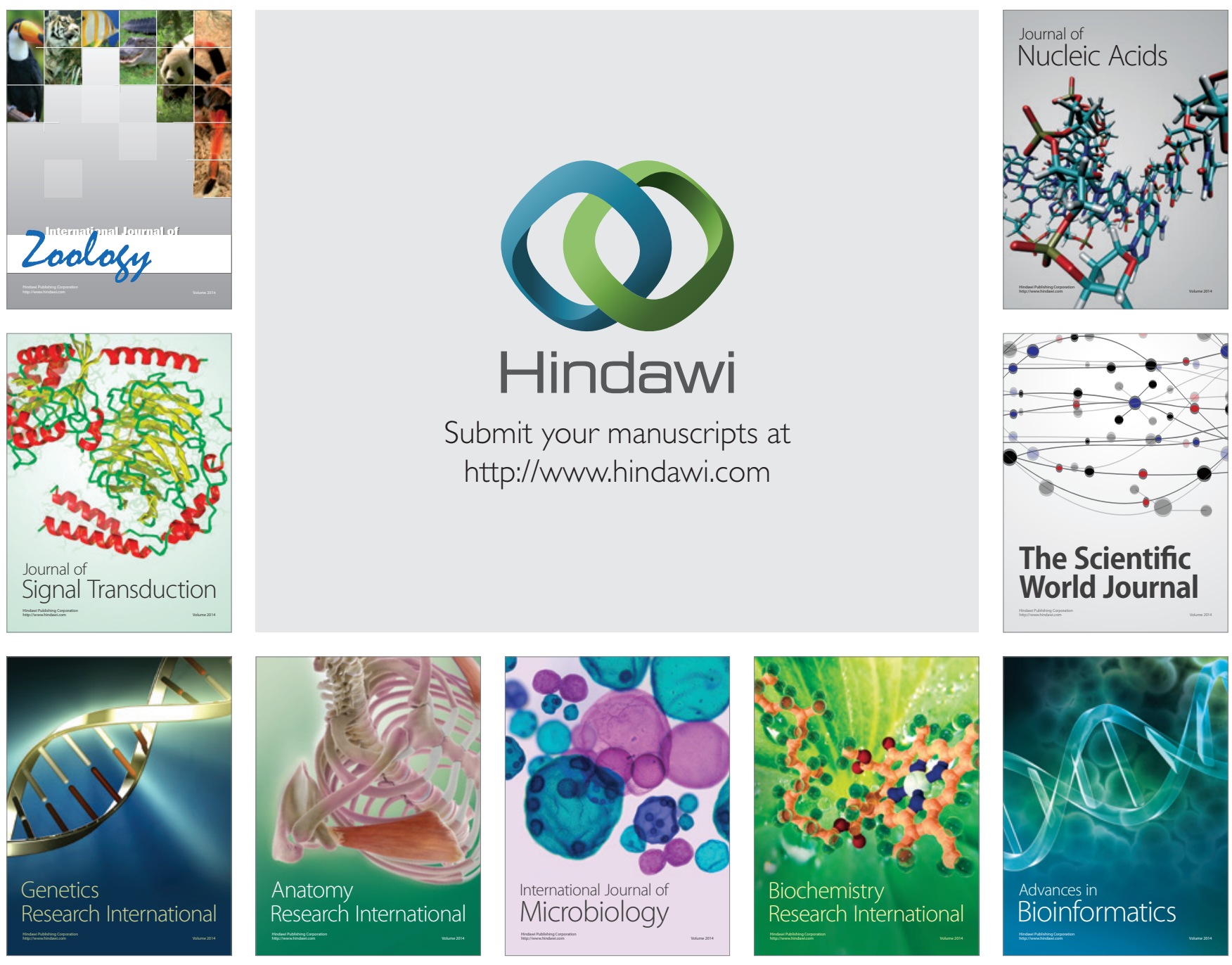

The Scientific World Journal
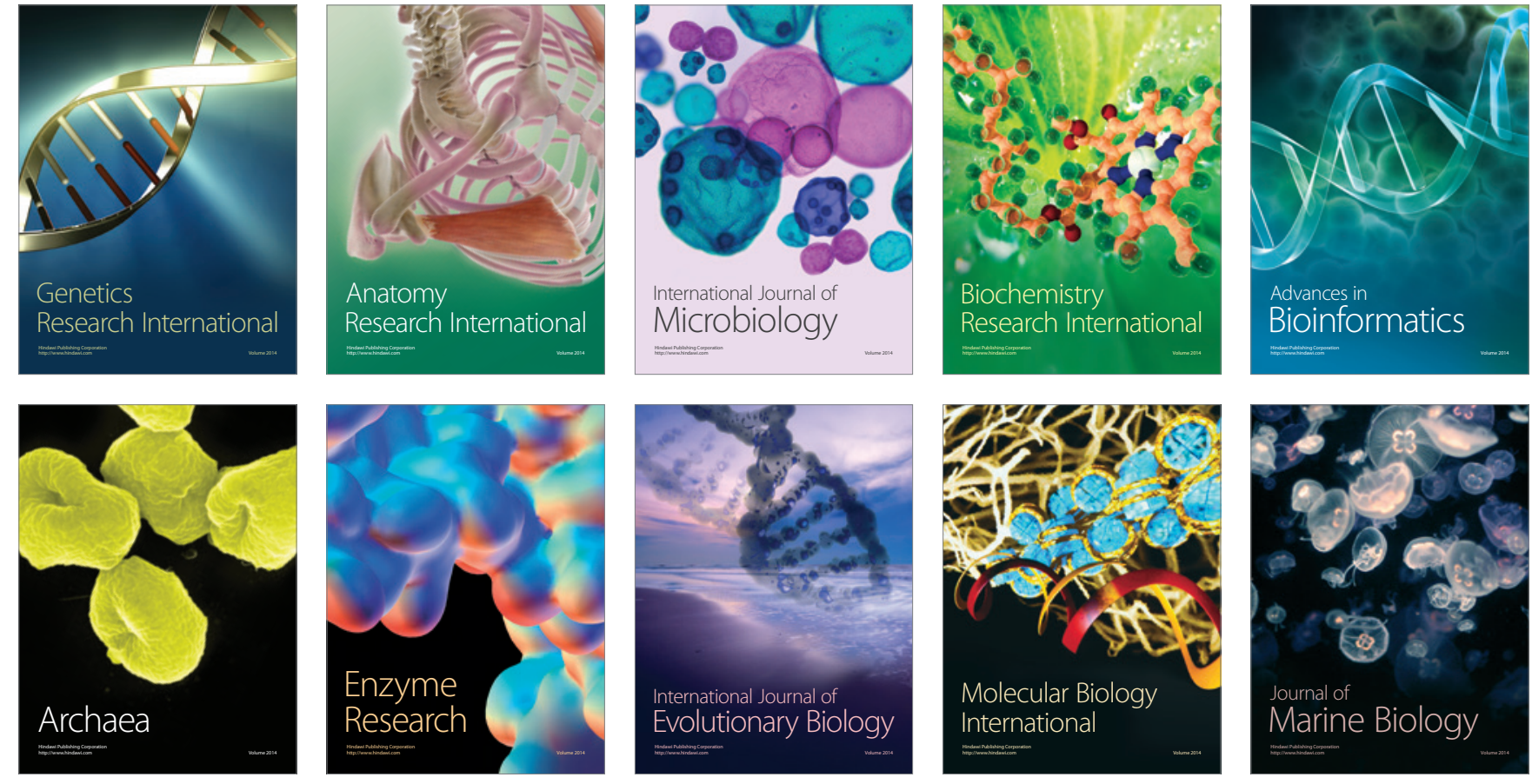